EGU2020-14347

https://doi.org/10.5194/egusphere-egu2020-14347

EGU General Assembly 2020

(c) Author(s) 2021. This work is distributed under

the Creative Commons Attribution 4.0 License.

\title{
Towards the first circumarctic N2O budget - Extrapolating to the landscape scale
}

\author{
Lona van Delden ${ }^{1}$, Maija Marushchak ${ }^{1,2}$, Carolina Voigt ${ }^{3}$, Guido Grosse ${ }^{4}$, Alexey Faguet ${ }^{5}$, Nikolay \\ Lashchinskiy $^{5,6}$, Johanna Kerttula ${ }^{1}$, and Christina Biasi ${ }^{1}$ \\ ${ }^{1}$ University of Eastern Finland, Kuopio, Finland (christina.biasi@uef.fi) \\ ${ }^{2}$ Department of Biological and Environmental Science, University of Jyväskylä, Jyväskylä, Finland \\ ${ }^{3}$ Department of Geography, University of Montréal, Montréal, Canada \\ ${ }^{4}$ Alfred Wegener Institute, Helmholtz Centre for Polar and Marine Research, Potsdam, Germany \\ ${ }^{5}$ Trofimuk Institute for Petroleum Geology and Geophysics, SB RAS, Russia \\ ${ }^{6}$ Central Siberian Botanical Garden SB RAS, Novosibirsk, Russia
}

The Arctic is warming at twice the rate of the rest of the globe. While it has been increasingly highlighted that thawing permafrost accelerates soil organic matter decomposition, research on biogeochemical $\mathrm{N}$ cycling is still underrepresented. Arctic nitrous oxide $\left(\mathrm{N}_{2} \mathrm{O}\right)$ emissions have long been assumed to have a negligible climatic impact but recently increasing evidence has emerged of $\mathrm{N}_{2} \mathrm{O}$ hotspots in the Arctic. Even in small amounts, $\mathrm{N}_{2} \mathrm{O}$ has the potential to contribute to climate change due to it being nearly 300 times more potent at radiative forcing than $\mathrm{CO}_{2}$. Therefore, the 'NOCA' project aims to establish the first circumarctic $\mathrm{N}_{2} \mathrm{O}$ budget. Following intensive $\mathrm{N}_{2} \mathrm{O}$ flux sampling campaigns at primary sites within Northern Russia and soil $\mathrm{N}_{2} \mathrm{O}$ concentration measurements from secondary sites across the Arctic, we are now entering the phase of spatial extrapolation. Challenges to overcome are the small-scale heterogeneity of the landscape and incorporating small features that can function as $\mathrm{N}_{2} \mathrm{O}$ hotspots. Therefore, as a first step in upscaling the $\mathrm{N}_{2} \mathrm{O}$ fluxes, high resolution imagery is needed. We show here novel highresolution 3D imagery from an unmanned aerial vehicle (UAV), which will be used to upscale $\mathrm{N}_{2} \mathrm{O}$ fluxes from plot to landscape scale by linking ground-truth $\mathrm{N}_{2} \mathrm{O}$ measurements to vegetation maps. This approach will first be applied to the East cliff of Kurungnakh Island in the Lena River Delta of North Siberia and is based on 2019 sampling campaign data. Kurungnakh Island is characterized by ice- and organic-rich Yedoma permafrost that is thawed by fluvial thermo-erosion forming retrogressive thaw slumps in various stages of activity. Overall, 20 sites were sampled along the cliff and inland, covering the significant topographic and vegetative characteristics of the landscape. The data from this scale will provide the basis for extrapolating, by using a stepwise upscaling approach, to the regional and finally circumarctic scale, allowing a first rough estimate of the current climate impact of $\mathrm{N}_{2} \mathrm{O}$ emissions from permafrost affected soils. Available international circumarctic data from this and past projects will be synthesized with an Arctic $\mathrm{N}_{2} \mathrm{O}$ database under development for use in future ecosystem and process-based climate model simulations. 
